\title{
Modelling site quality and individual-tree growth in pure and mixed Pinus brutia stands in north-east Greece
}

\author{
Marc PALAhI $^{1 *}$, Timo PUKKALA ${ }^{2}$, Dimitrios KASIMIADIS $^{3}$, Konstantinos PoIRAZIDIS $^{3}$, \\ Aristotelis C. PAPAGEORGIOU ${ }^{3}$ \\ ${ }^{1}$ European Forest Institute, Mediterranean Regional Office, Passeig Lluis Companys, 23, 08010 Barcelona, Spain \\ ${ }^{2}$ ForEcoTechnologies, Av. Diagonal 416, Estudio 2, 08037 Barcelona, Spain \\ ${ }^{3}$ Democritos University of Thrace, Department of Forestry, Environmental Management and Natural Resources, \\ Pantazidou 193, 68200 Orestiada, Greece
}

(Received 12 June 2007; accepted 5 March 2008)

\begin{abstract}
-
-Simulation tools, based on individual tree growth and mortality models can produce the most detailed predictions of forest stand development under different management schedules. These models allow the manager to predict the development of any type of stand (even- and uneven-aged, and pure and mixed stands).

- Different model approaches and predictors are required for pure even-aged or mixed uneven-aged forest stands. This study developed and compared two sets of models which enable tree-level simulation of the development of pure and mixed stands of Pinus brutia in north-east Greece. The first set of models for even-aged forestry consists of site index models, diameter growth models, tree height models, and mortality models. The second set, which is for uneven-aged forestry, uses a past growth index instead of a site index.

- The simulations and overall fitting statistics suggest that the two types of models provide realistic and accurate predictions of forest stand development and allow one to simulate the development of complex Pinus brutia stand structures in Dadia National Park forests.

- The advantages of the two approaches are discussed and it is suggested that the growth index is an effective predictor of site quality and the set of models which used such variable as predictor performed in a similar way as the models using site index, which require more information and a given stand structure (even-aged).
\end{abstract}

growth and yield / mixed models / simulation

Résumé - Modélisation de la qualité des stations et de la croissance individuelle des arbres dans des peuplements purs et mélangés de Pinus brutia dans le nord-est de la Grèce.

- Des outils de simulation basés sur la croissance individuelle des arbres et des modèles de mortalité peuvent produire les prédictions les plus détaillées sur le développement des peuplements forestiers sous différents programmes de gestion. Ces modèles permettent au gestionnaire de prédire le développement de n'importe quel type de peuplement (équienne et inéquienne, peuplement pur et peuplement mélangé).

- Différents modèles d'approche et des indices sont requis pour les peuplements purs équiennes ou les peuplements mélangés inéquiennes. Cette étude a développé et comparé deux séries de modèles qui permettent la simulation, au niveau de l'arbre, du développement des peuplements purs et mélangés de Pinus brutia dans le nord-est de la Grèce. La première série de modèles pour la sylviculture équienne consiste en modèles de site index, modèles de croissance en diamètre, modèles de croissance en hauteur et modèles de mortalité. La seconde série destinée à une sylviculture inéquienne, utilise un index de croissance passée au lieu d'un site index.

- Les simulations et des statistiques d'ajustement d'ensemble suggèrent que les deux types de modèles fournissent des prédictions réalistes et précises du développement des peuplements forestiers et permettent de simuler le développement des structures complexes des peuplements de Pinus brutia du Parc National de Dadia.

- Les avantages des deux approches sont discutés et il est suggéré que l'index de croissance est un indice de la qualité de la station et la série de modèles qui utilise ce genre de variables comme indice opère d'une manière similaire à celle des modèles utilisant les site index, qui demandent plus d'information et une structure donnée de peuplement (équienne).

croissance et production / modèles mixtes / simulation

\section{INTRODUCTION}

Dadia National Park (Dadia NP) is a part of the South Eastern edge of the Rodopi mountains and is one of the most emblematic natural heritage sites in north-east of Greece.
The National Park includes two strictly protected core areas (7290 ha) where the main functions are nature conservation, environmental education and scientific research, and one buffer zone ( $35170 \mathrm{ha}$ ) in which forestry is the main activity. In addition, other activities such as domestic livestock grazing, traditional agriculture, nature-oriented tourism, and

* Corresponding author: marc.palahi@efi.int 
Table I. Summary of stand characteristics of the 32 oak-dominated and 40 pine-dominated plots used for modelling the dominant height growth of oaks and $P$. brutia. Six plots were not clearly dominated by any of the species. The stand characteristics are given for the beginning of the growth period. Plots were measured two times ${ }^{\mathrm{a}}$.

\begin{tabular}{|c|c|c|c|c|}
\hline Variable & Mean & Standard deviation & Minimum & Maximum \\
\hline \multicolumn{5}{|l|}{ Oaks } \\
\hline$T(\mathrm{y})$ & 45.2 & 18.7 & 24.3 & 96.5 \\
\hline$H_{\text {dom }}(\mathrm{m})$ & 8.0 & 1.9 & 4.7 & 12.2 \\
\hline$G\left(\mathrm{~m}^{2} \mathrm{ha}^{-1}\right)$ & 18.6 & 10.1 & 2.6 & 46.4 \\
\hline$N_{\text {trees }}\left(\right.$ trees $\left.\mathrm{ha}^{-1}\right)$ & 1029.7 & 564.2 & 290.0 & 2150.0 \\
\hline$D_{G},(\mathrm{~cm})$ & 21.2 & 8.9 & 10.7 & 41.0 \\
\hline \multicolumn{5}{|l|}{ Pinus brutia } \\
\hline$T(\mathrm{y})$ & 47.0 & 25.9 & 10.9 & 103.8 \\
\hline$H_{\text {dom }}(\mathrm{m})$ & 12.7 & 3.5 & 5.8 & 20.7 \\
\hline$G\left(\mathrm{~m}^{2} \mathrm{ha}^{-1}\right)$ & 23.6 & 8.7 & 4.6 & 49.0 \\
\hline$N_{\text {trees }}\left(\right.$ trees ha $\left.{ }^{-1}\right)$ & 1085.7 & 623.5 & 290 & 2400 \\
\hline$D_{G}(\mathrm{~cm})$ & 23.9 & 8.9 & 10.0 & 41.0 \\
\hline
\end{tabular}

${ }^{a} T$ : stand age; $H_{d o m}$ : dominant height; $G$ : stand basal area; $N_{\text {trees }}:$ the number of trees per hectare; $D_{G}:$ mean diameter.

improvement of habitats for birds of prey are allowed in the area (Adamakopoulos et al., 1995).

Dadia NP remains well preserved and is well known by its high biological diversity in terms of plant and animal species (e.g., high number of raptor species), which are favored by the park's mosaics of heterogeneous forested habitats (Kati et al., 2004; Poirazidis et al., 2002; 2004; 2007; Schindler et al., 2007).

In view of the importance of Dadia forests, there is a need for a reliable system of growth and yield predictions that, with appropriate economic parameters and ecological models, will support multifunctional forest management and planning. Traditionally, the prediction of forest growth and yield in Greece has been mainly based on experience, historical records or extrapolation from yield tables developed for specific forestry conditions (Apatsidis, 1995; Kossenakis, 1939). However, these approaches may not be sufficient when developing sound management plans for complex forest systems (mixed and any-aged stands). Chatziphilippidis and Spyroglou (2006) developed the first individual-tree growth model for Greece (for Quercus frainetto) and proposed the use of modern modelling approaches to predict forest stand development in Greece to efficiently address current forest management situations. Of the modelling approaches, individual-tree growth modelling is the one enabling a more flexible and detailed simulation of the complex structures of Mediterranean forests and their dynamics. Several researchers have developed individual-tree growth models for different tree species and forest conditions for other Mediterranean tree species and regions (Calama and Montero, 2005; Palahí and Grau Corbí, 2003; Palahí et al., 2003; Sanchez-Gonzalez et al., 2005; Soares and Tomé, 2003; Trasobares et al., 2004a; 2004b).

The aim of this study was to develop a set of models that enable tree-level distance-independent simulation of $P$. brutia and accompanying oaks in mixed and pure stands in Dadia NP. The system consists of diameter growth models, static height models, and models for the probability of a tree to survive for the coming 5-year period. Site quality was modelled using two different approaches; (i) a site index model (ii) a past growth index. Therefore, two model sets were developed, which differed in the method to estimate site quality. The model set that uses a past growth index is suitable for uneven-aged forestry since it does not require stand age and dominant height as predictors.

\section{MATERIALS AND METHODS}

\subsection{Data}

The data were measured in 78 permanent sample plots established in 2000 by WWF-Greece to inventory and obtain scientific data from Dadia forest for a systematic Monitoring Plan (Poirazidis et al., 2002), which belongs mainly to the villages of Dadia, Lefkimi, and

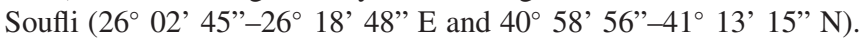
The plots, located at altitudes ranging from 25 to $458 \mathrm{~m}$ a.s.l., were re-measured in 2005. The plots represented different degrees of mixture (including pure stands) between $P$. brutia and different oak species. The main oak species present were Quercus frainetto, Quercus pubescens, Quercus cerris and Quercus sessiliflora. P. nigra trees were also found in mixture with $P$. brutia and oaks. Some planted $P$. pinaster trees were also present in even-aged stands. The site index (dominant height at 100 years) of pine-dominated stands ranged from $8 \mathrm{~m}$ to 24 and the site index of oak-dominated stands varied from 7 to $21 \mathrm{~m}$ (Tab. I), when calculated with the models presented in this study. The mean plot area was 0.06 ha. The area of the plots ranged between 0.02 ha and 0.1 ha depending on the stand density. At each measurement, tree diameter at $1.3 \mathrm{~m}$ height $(\mathrm{dbh})$ and tree heights from all trees thicker than $5 \mathrm{~cm}$, as well as tree age of at least 20 trees per plot were recorded. The past 5-year growth was also measured from the sample trees. In the first measurement, tree diameters were recorded with an accuracy of one $\mathrm{cm}$ (rounded to the closest full centimetre). In the second measurement, girths were measured with one$\mathrm{mm}$ accuracy and converted to diameter. Dead trees were recorded. 
Table II. Mean, Standard deviation (S.D.) and range of main characteristics in the study material used to develop the individual-tree growth and mortality models ${ }^{\mathrm{a}}$.

\begin{tabular}{|c|c|c|c|c|c|}
\hline Variable & $N$ & Mean & S.D. & Minimum & Maximum \\
\hline \multicolumn{6}{|c|}{ Pinus brutia } \\
\hline \multicolumn{6}{|c|}{ Diameter increment and height models (Eqs. (4), (6), (7), (8), (9)) } \\
\hline$i d 5$ (cm per 5 years) & 1502 & 2.16 & 1.17 & -1.20 & 5.90 \\
\hline$h(\mathrm{~m})$ & 1502 & 10.45 & 3.93 & 1.30 & 25.10 \\
\hline$d(\mathrm{~cm})$ & 1502 & 19.92 & 11.01 & 6.80 & 68.00 \\
\hline$B A L\left(\mathrm{~m}^{2} / \mathrm{ha}\right)$ & 1502 & 15.40 & 9.06 & 0.00 & 46.83 \\
\hline Soil depth $(\mathrm{cm})$ & 69 & 48.30 & 17.68 & 0.00 & 75.00 \\
\hline GI & 69 & 0.99 & 0.35 & 0.42 & 2.26 \\
\hline$G\left(\mathrm{~m}^{2} / \mathrm{ha}\right)$ & 69 & 25.11 & 8.35 & 4.63 & 49.03 \\
\hline$S I(\mathrm{~m})$ & 40 & 17.13 & 3.51 & 7.99 & 23.80 \\
\hline \multicolumn{6}{|c|}{ Mortality model (Eq. (10)) } \\
\hline$P$ (survive) & 1710 & 0.89 & 0.30 & 0.00 & 1.00 \\
\hline$G\left(\mathrm{~m}^{2} / \mathrm{ha}\right)$ & 69 & 25.18 & 8.51 & 4.63 & 49.03 \\
\hline$d(\mathrm{~cm})$ & 1710 & 19.31 & 11.02 & 6.80 & 68.00 \\
\hline \multicolumn{6}{|c|}{ Oaks } \\
\hline \multicolumn{6}{|c|}{ Diameter increment and height models (Eqs. (5), (6), (7), (8), (9)) } \\
\hline$i d 5$ (cm per 5 years) & 1992 & 1.34 & 0.82 & -1.80 & 5.30 \\
\hline$h(\mathrm{~m})$ & 1992 & 7.68 & 2.44 & 1.80 & 19.00 \\
\hline$d(\mathrm{~cm})$ & 1992 & 12.33 & 4.84 & 6.00 & 59.00 \\
\hline$B A L\left(\mathrm{~m}^{2} / \mathrm{ha}\right)$ & 1992 & 13.77 & 8.30 & 0.00 & 46.18 \\
\hline Soil depth $(\mathrm{cm})$ & 78 & 50.10 & 19.46 & 0.00 & 75.00 \\
\hline Elevation (m) & 78 & 199.18 & 82.27 & 0.00 & 458.00 \\
\hline$G\left(\mathrm{~m}^{2} / \mathrm{ha}\right)$ & 78 & 18.91 & 8.70 & 2.60 & 46.41 \\
\hline$G I$ & 78 & 0.99 & 0.30 & 0.42 & 2.10 \\
\hline$S I(\mathrm{~m})$ & 32 & 12.35 & 2.82 & 7.13 & 21.45 \\
\hline \multicolumn{6}{|c|}{ Mortality model (Eq. (11)) } \\
\hline$P$ (survive) & 2115 & 0.95 & 0.22 & 0.00 & 1.00 \\
\hline$G\left(\mathrm{~m}^{2} / \mathrm{ha}\right)$ & 78 & 17.70 & 7.56 & 2.60 & 46.41 \\
\hline$d(\mathrm{~cm})$ & 2115 & 12.30 & 4.90 & 6.00 & 59.00 \\
\hline
\end{tabular}

${ }^{a} N$ : the number of observations at tree-, and plot-level; id5: 5-year diameter increment; $d$ : diameter at breast height; $B A L$ : Basal area of larger trees from the subject tree (competition index); $G$ : stand basal area; SI: site index; $h$ : tree height; $G I$ : growth index; $P$ (survive): probability of a tree surviving.

The measurements resulted in 1502 pine observations and 1992 oak observations for modelling diameter increment and tree height. Only the second measurement was used to develop the tree height models (Tab. II).

\subsection{Site quality evaluation}

One of the most important tasks when modelling and predicting forest stand development is estimating the site quality. Because of the importance of effective evaluation of site quality, much effort has been devoted to the development of techniques for quantifying site quality (Clutter et al., 1983). Clutter et al. (1983) classified these methods in (i) direct methods and (ii) indirect methods. Direct methods require the existence of the species of interest at the particular location where site quality is to be evaluated, while indirect methods are based on indirect information such as lesser vegetation characteristics or topographic, climatic or edaphic factors.

The most commonly used direct method for estimating site quality relies on site index curves (Clutter et al., 1983). Examples of individual-tree models using site index or related variables (dominant height increment, or dominant height together with stand age) as a predictor of site quality are various (Calama and Montero, 2005; Palahí et al., 2003; Sanchez-Gonzalez et al., 2005). However, in uneven-aged stands the dominant height-age relationship cannot be used because stand-age is "by definition" undefined. The approach is also problematic in mixed stands when none of the species is clearly dominant. In these situations, another possibility is to obtain site information from topographic descriptors such as elevation, slope, aspect, location descriptors (e.g., latitude) and soil type (which are indirect methods). Vanclay (1994) and Trasobares et al. (2004b) 
proposed another approach which can be used as alternative or as complementary to the use of indirect methods. Such method was based on a growth index. The index requires a model for predicting the past diameter or radial growth of sample trees from tree size and competition variables but without using site variables. The model predicts the so-called normal growth, or the growth of an average site. The growth index is obtained as a ratio of measured past growth of sample trees and the predicted past growth of the same trees. The use of this kind of growth index requires measuring the past growth of a few sample trees per stand. The method can be applied in anyaged forest and does not require information on dominant height and stand age. Trasobares et al. (2004b) used such growth index as a predictor in individual-tree diameter growth models for $P$. halepensis in Catalonia.

\subsubsection{Growth index model}

Following the approach tested by Trasobares et al. (2004b), a linear regression model for the past radial growth was developed using the ordinary least squares (OLS) technique in SPSS (SPSS Inc., 2005). Several predictors describing tree size (diameter at breast height) and competition variables (basal area, number of trees per hectare, basal area of larger trees than the subject tree) and their transformations were tested as potential predictors since they are the main factors explaining diameter growth (apart form site). Many competition indices have been developed and tested in order to quantify in a simple expression, the effects of neighbouring trees on the growth of an individual in a forest stand (Vanclay, 1994). Competition variables may represent two-sided competition such as stand basal area $(G)$ or number of trees per hectare, or one-sided competition, which is analogous in many respects to the available light used in many succession and process models, represented by many competition indices like the basal area of larger trees than the subject tree (Vanclay, 1994).

The final predictors had to be logical and significant at the 0.05 level without any systematic errors in the residuals.

The models for the past 5-year diameter increment were as follows:

\section{Pinus brutia}

$$
\begin{aligned}
i d 5_{\text {past }}= & 3.243-0.028 d-0.244 \ln G-0.107 B A L / \ln (d+1) \\
& +0.459 \text { MariPine }
\end{aligned}
$$

Oaks

$$
i d 5_{\text {past }}=0.851-0.073 \ln (B A L=1)
$$

where $i d 5_{\text {past }}$ is the past 5 -year diameter growth $(\mathrm{cm}), d$ is diameter $(\mathrm{cm}), G$ is stand basal area $\left(\mathrm{m}^{2} \mathrm{ha}^{-1}\right), B A L$ is the basal area of trees larger than the subject tree $\left(\mathrm{m}^{2} \mathrm{ha}^{-1}\right)$, and MariPine is a dummy variable which is equal to one if the tree is maritime pine ( $P$. pinaster) and zero otherwise.

Once the past growths of the sample trees were predicted with the above models the ratio between the measured and predicted past growth was calculated for all sample trees. The growth index of a plot was the average of the past growth ratios of sample trees.

\subsubsection{Site index modelling}

The difference equation method was used to model the dominant height growth of Pinus brutia and the oak species present in Dadia forests (Tab. III). Ten difference equations derived from the functional forms of the Chapman Richards function (Pienaar and Turnbull, 1973), the Lundquist-Korf function (cited in Palahí and Grau Corbí, 2003), the Schumacher function (Schumacher, 1939), and the Hosffeld function (cited by Palahí et al., 2004; Pita, 1964) together with the McDill-Amateis function (McDill and Amateis, 1992), were selected as candidate functions (see Tab. III).

The difference equations were fitted using the non-linear leastsquares (NLS) technique in SPSS (SPSS Inc., 2005). The SPSS software uses the Levenberg-Marquard algorithm to obtain the final parameter estimates. The loss function was defined as the sum of squared residuals (observed minus predicted values). The statistical procedure assumed that the error term is normally distributed with zero mean, constant variance, and independence between cases. Due to the limitations of the modelling data (one growth period and unbalanced data for different ages and sites), the selection of the site index model was mainly based on qualitative examinations as addressed by Palahí et al. (2004). The asymptotic parameter and the biological realism and graphical appearance of the candidate site index curves were examined to discard biologically non-realistic models. In addition, the quality of extrapolations outside the range of the modelling data and the growth pattern at young ages were analysed.

The selected site index models for both $P$. brutia and oak used the McDill-Amateis function (Eq. (3)):

$$
\operatorname{Hdom}_{2}=\frac{\beta_{1}}{1-\left(1-\frac{\beta_{1}}{\text { Hdom }_{1}}\right) \times\left(\frac{T_{1}}{T_{2}}\right)^{\beta_{2}}}
$$

where subscripts 1 and 2 refer to time points 1 and $2, \beta_{1}$ is the asymptote parameter, $\beta_{2}$ is a growth rate/shape parameter, $T$ is stand age (years) and Hdom is dominant height (m). Difference equations (such as Eq. (3)) are dynamic equations representing a continuous fourvariable prediction system directly interpreting three-dimensional surfaces without explicit knowledge of the third dimension (site quality), which depends on an unobservable variable (Cieszewski and Bailey, 2000).

Site index can be calculated from Equation (3), by replacing $T_{2}$ by the reference age (index age was taken as 100 years), and $H_{d o m_{1}}$ and $T_{1}$ by the observed dominant height and age in the subject stand.

\subsection{Diameter increment modelling}

The biological processes that influence tree growth are inherently non-linear. However, linear regression is a suitable tool for modelling growth curves if a linearizing relationship can be found between the key variables and biologically reasonable shapes are determined (Trasobares et al., 2004b). Variables representing tree size, competition and site quality are required to explain the main factors affecting diameter growth. Appropriate transformations of tree dbh were used to try to obtain the typical pattern of tree growth processes, where diameter increment increases to a maximum early in the life of a tree and then slowly decreases, approaching zero as the tree matures. Competition can be represented by different variables, some representing two-sided competition (stand basal area or number of trees per hectare) some representing one sided competition (like relative size variables, dbh/dmean or the basal are of larger trees than the subject tree $(B A L)$ ). Wycoff (1990) found $B A L$ to be a good predictor of tree basal area increment and more appropriate than relative size predictors, since the latter would be influenced by harvesting and could predict a non-logical response to thinning from below. 
Table III. Candidate equations for dominant height modeling.

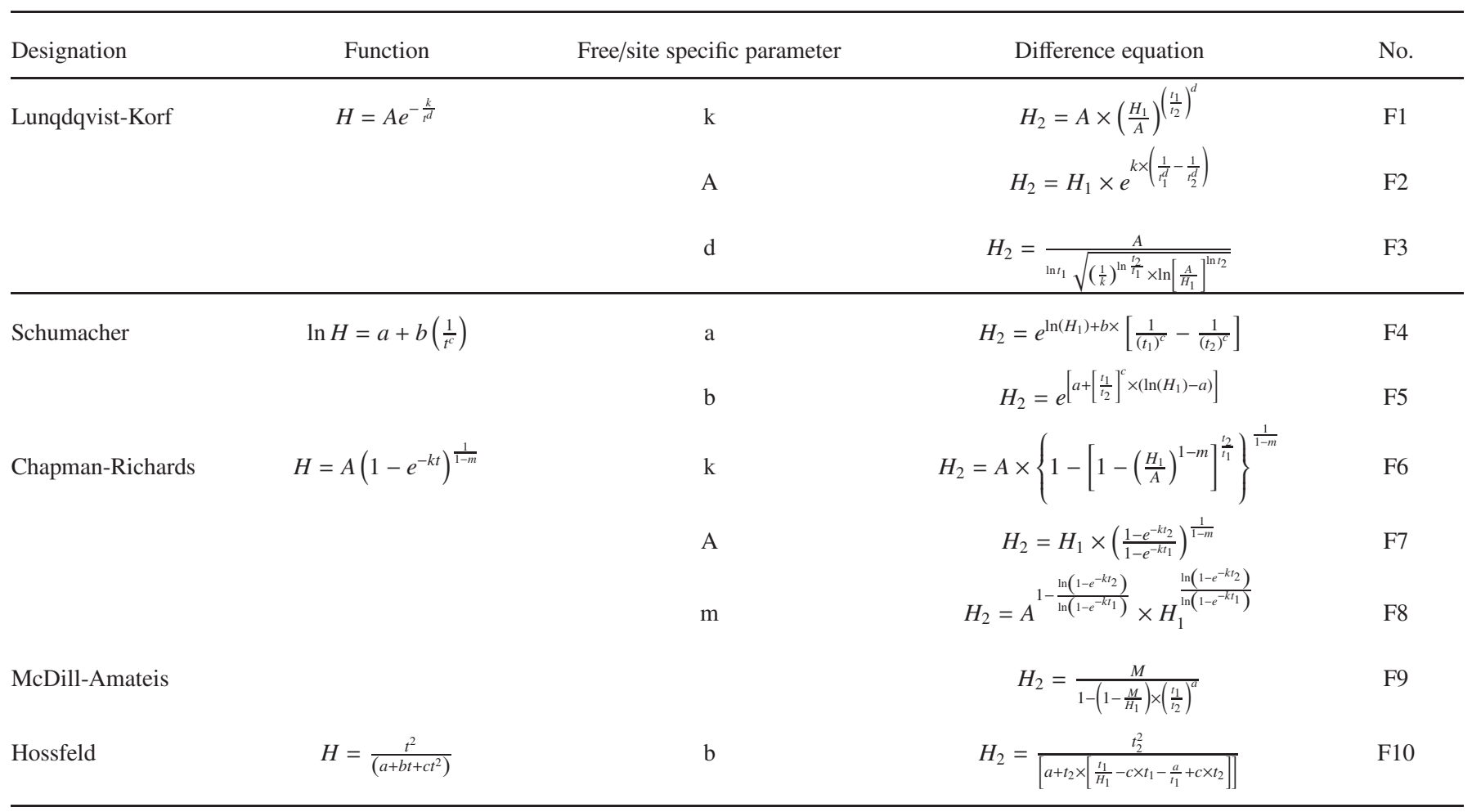

The predictors were chosen from tree-level ( $d b h, B A L$, etc.), standlevel (basal area, number of trees per hectare, etc.), and site characteristics as well as their transformations based on the available data and their biological significance to tree diameter growth. Criteria for including explanatory variables were the logical sign of the parameter, the level of significance of the parameters and the reduction in the mean square error. Two sets of diameter growth models, one for $P$. brutia and another one for the oak species present in the Dadia NP were prepared by using either the growth index or the site index as predictors. The predicted variable was the five-year diameter growth. This was obtained as a difference between two successive diameter measurements. Due to errors in measuring dbh and the $1-\mathrm{cm}$ accuracy in the first measurement, several growths were negative. Therefore, it was not possible to model the logarithmic transformation of growth.

Due to the hierarchical structure of the data (i.e., trees are grouped into plots), the generalised least-squares (GLS) technique was applied to fit a mixed linear regression model. The models were estimated using the maximum likelihood procedure of the computer software SPSS (SPSS Inc., 2005). All predictors had to be significant at the 0.05 level without any systematic errors in the residuals.

The P. brutia (Eq. (4)) and oak (Eq. (5)) diameter growth models were as follows:

$$
\begin{aligned}
& i d 5_{k j}=\beta_{0}+\beta_{1} \times d_{k j}+\beta_{2} \times B A L_{k j}+\beta_{3} \times \ln \left(d_{k j}\right)+u_{k}+e_{k j} \\
& i d 5_{k j}=\beta_{0}+\beta_{1} \times \text { Ele }_{k}+\beta_{2} \times \ln \left(G_{k}\right)+u_{k}+e_{k j}
\end{aligned}
$$

where $i d 5$ is future diameter growth (cm per 5 years); $d$ is diameter at breast height $(\mathrm{cm}), B A L$ is competition index measuring the total basal area of larger trees $\left(\mathrm{m}^{2} \mathrm{ha}^{-1}\right), G$ is stand basal area $\left(\mathrm{m}^{2} \mathrm{ha}^{-1}\right)$ and Ele is elevation (m). Subscripts $k$ and $j$ refer to plot $k$ and tree $j$, respectively. $u_{k}$ and $e_{k j}$ are independent and identically distributed random between-plot and within-plot factors with a mean of 0 and constant variances of $\sigma_{p l}^{2}, \sigma_{e}^{2}$, respectively. These variances and the parameters $\beta_{i}$ were estimated using the GLS method.

It turned out that site index and growth index were not significant predictors because the random plot factors accounted for the effect of site. However, the random plot factors $u_{k}$ of the models (Eqs. (4) and (5)) correlated with the site factors. In order to include the effects contained in plot factors in simulations, models for predicting the plot factor were developed using the ordinary last squares (OLS) technique in SPSS (SPSS Inc., 2005). Two different models were fitted, one using site index (SI) (Eq. (6)) and another using growth index $(G I)($ Eq. (7)) as a predictor:

$$
\begin{aligned}
& u_{k}=\beta_{0}+\beta_{1} \times \text { Sdepth }+\beta_{2} \times S I+e_{k} \\
& u_{k}=\beta_{0}+\beta_{1} \times S \text { depth }+\beta_{2} \times G I+e_{k}
\end{aligned}
$$

where $u_{k}$ is plot factor, Sdepth is soil depth (cm), SI is site index (m) and $G I$ is past growth index (no unit).

\subsection{Height modeling}

The second measurement which was more accurate than the first measurement was used to develop static height models for Pinus brutia and oaks. Two types of models were fitted; (i) a non-linear height model to be used with site index curves (even-aged stands) (Hynynen, 1995), and (ii) a Hossfeld-type model (Peschel, 1938) using the past growth index as a predictor (uneven-aged stands). The models were estimated using a nonlinear least squares (NLS) technique in SPSS (SPSS Inc., 2005). 
The non-linear height models for $P$. brutia and oaks using the two approaches (even-aged, Eq. (8); uneven-aged, Eq. (9)) were as follows.

$$
\begin{aligned}
& h_{k j}=1.3+\left(H_{d o m, k}-1.3\right) \times\left(\frac{d_{k j}}{D_{d o m_{k}}}\right)^{\left(\beta_{0}+\beta_{1} \times\left(\frac{d_{k j}}{D_{d o m_{k}}}\right)\right)}+e_{k j} \\
& h_{k j}=\left(\frac{\beta_{0}+\beta_{1} / G I_{k}}{1+\beta_{3} / d_{k j}+\beta_{2} / d_{k j}^{2}}\right)+e_{k j}
\end{aligned}
$$

where $h$ is tree height $(\mathrm{m})$ and $D_{d o m}$ is dominant diameter $(\mathrm{cm})$ of the stand.

\subsection{Survival modelling}

Two major categories of natural mortality can be distinguished: regular and catastrophic mortality. Regular mortality refers principally to ageing, suppression and competition, but also mortality arising from "chance" and from normal incidence of pests, diseases, and weather phenomena (Vanclay, 1994). Catastrophic mortality includes wildfires (see González et al., 2007), occasional but severe losses from "abnormal" weather conditions, and major pest and disease outbreaks. In this study, individual tree regular mortality was accounted for by modelling the probability of a tree to survive for the coming 5-year period. The data for modelling the survival probability as a function of tree and stand characteristics were obtained by coding survivals as ones and dead trees (living in the first measurement and dead in the second measurements) as zeroes. This resulted in 1532 pine survivals, 2007 oak survivals, 178 dead pines, and 108 dead oaks. Since mortality is a discrete event, i.e. only the values 0 (dead) or 1 (alive) may occur, the logistic function was used (Vanclay, 1994). The candidate variables for the mortality models represented factors that are considered to explain the probability of survival; (i) individual tree size, (ii) tree competition (one- and two-sided competition) (ii) and site quality. Tree age was not tested since that variable was not measured for all trees in the plot. The final models included significant and logical predictors from these groups of variables to obtain a biologically consistent model. The following survival models for $P$. brutia (Eq. (10)) and oaks (Eq. (11)) were estimated using the Binary Logistic procedure in SPSS (SPSS Inc., 2005).

$$
\begin{gathered}
P(\text { survive })_{k j}=\frac{1}{1+\exp \left(-\left(\beta_{0}+\beta_{1} \times \ln \left(d_{k j}\right)+\beta_{2} \times \ln \left(G_{k}\right)\right)\right)}+e_{k j} \\
P(\text { survive })_{k j}=\frac{1}{1+\exp \left(-\left(\beta_{0}+\beta_{1} \times \ln \left(G_{k}\right)+\beta_{2} \times \frac{1}{d_{k j}}\right)\right)}+e_{k j}
\end{gathered}
$$

where $P$ (survive) is the probability of a tree to survive for the next 5-year period.

\subsection{Ingrowth modelling}

A complete set of models to simulate the dynamics uneven-aged stands requires models for predicting the ingrowth. Different linear models (using different stand variables as predictors) were tested to predict the number of pines and oaks per hectare entering the first dbh-class during a five year period. However, none of the models tested was significant. Therefore, the mean number of pines and oaks entering the first dbh-class was used as the ingrowth model. The mean diameter of the trees entering the first dbh-class was also calculated to estimate the size of the ingrowth trees at the end of the 5-year period.
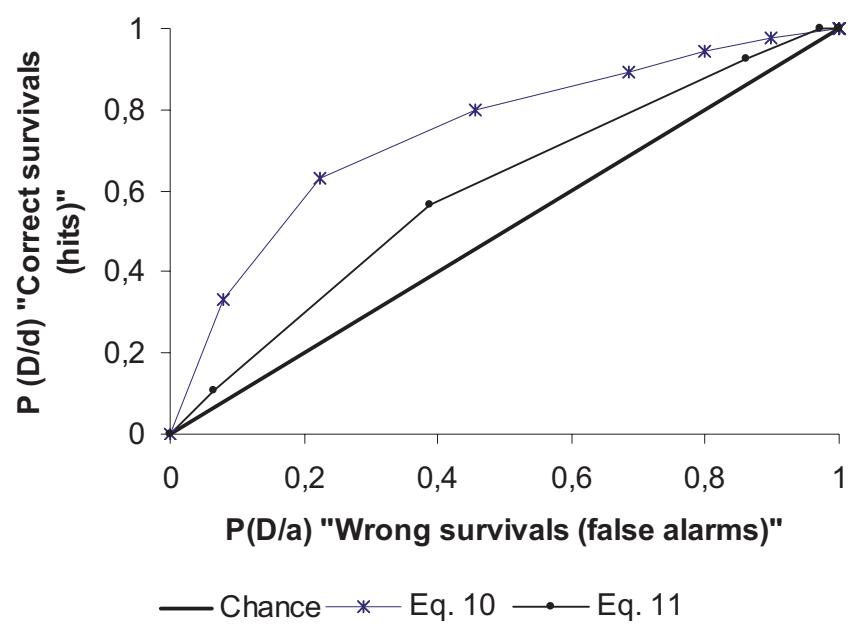

Figure 1. Receiver operating characteristic curves for Equations (10) and (11). $\mathrm{P}(\mathrm{D} / \mathrm{d})$ Hit is the hit rate, which equals to the number of trees predicted as alive and observed also alive from the total of trees observed as alive. $\mathrm{P}(\mathrm{D} / \mathrm{a})$ False Alarm is the false alarm rate, which equals to the number of trees predicted as alive but observed as dead from the total of trees observed as dead.

\subsection{Model evaluation}

The models were evaluated quantitatively by examining the magnitude and distribution of residuals for combinations of variables. Absolute and relative biases and root mean square error (RMSE) were also calculated.

To evaluate the performance of the survival models the so-called receiver operating characteristic (ROC) curves (Saveland and Neuenschwander, 1990) were calculated by gradually changing the threshold probability (called as "decision criterion") from zero to one, and with every threshold calculating the numbers of predicted survivals and predicted dead trees, separately for observed survivors and observed dead trees (Fig. 1). The ROC curves are derived from plotting the hit rate against the false alarm rate for different decision criteria (Saveland and Neuenschwander, 1990), the decision criterion being a threshold probability that determines if a tree is considered dead or alive. The positive diagonal, where the probability of a hit equals the probability of a false alarm, is what would be expected from a chance. The upper left-hand corner, where probability of hit equals one and the probability of a false alarm is zero, represents perfect performance. The close a curve comes to the upper left-hand corner, the better the decision system.

The models were further evaluated and their use illustrated by simulating the development of four representative stands picked from the study material: two even-aged pine stands, one even-aged oak stand and one even-aged mixed stand. In addition, an uneven-aged mixed stand was selected to illustrate the use of the whole set of models in long-term simulation. The development of the plots was simulated in 5-year steps as follows:

1. Multiply the frequency of each tree (number of trees per hectare that a tree represents) by the 5-year survival probability. The survival probability is calculated by Equation (10) or (11).

2. For each tree, calculate the 5-year diameter increment (Eqs. (47)) and add it to the diameter; increment tree ages by 5 years. 
Table IV. Estimates of the parameters, degree of determination $\left(R^{2}\right)$ and absolute and relative biases and RMSEs of the dominant height growth models (Eq. (3)) for P. brutia and oaks.

\begin{tabular}{lcc}
\hline Parameter & P. brutia & Oaks \\
\hline$\beta_{1}$ & 47.8000 & 24.8300 \\
$\beta_{2}$ & 0.5960 & 0.7440 \\
$R^{2} 0.9791$ & 0.9604 & \\
Bias & $0.0690 \mathrm{~m}$ & $0.0015 \mathrm{~m}$ \\
Bias \% & 0.5128 & 0.0182 \\
RMSE & $0.5751 \mathrm{~m}$ & $0.3997 \mathrm{~m}$ \\
$\%$ & 4.2719 & 4.7097 \\
\hline
\end{tabular}

3. If the set for even-aged forestry is used, calculate dominant height from the site index model and incremented stand age using Equation (3), and calculate the dominant diameter from incremented tree diameters.

4. If uneven-aged forestry is simulated, calculate ingrowth.

5. Calculate tree heights using Equation (8) or (9).

\section{RESULTS}

\subsection{Site index models}

The McDill-Amateis equation (Eq. (3)) was used to model dominant height growth of $P$. brutia and oak dominated stands. This function has the property of time invariant predictions ensuring that projections over the same period of time are equivalent, regardless of the length or number of projection intervals (Amaro et al., 1998). The coefficient of determination $\left(R^{2}\right)$ was 0.97 for P. brutia and 0.96 for the oak model (Tab. IV). The dominant height models had a relative bias of $0.51 \%$ (pine) and $0.02 \%$ (oak) and RMSE of $4.27 \%$ (pine) and $4.70 \%$ (oak). The two models produced a similar growth pattern for low site indices. For the best sites the dominant height model of oak produces a relatively fast growth at early ages but from 20 years onwards the growth decelerates to a rather constant rate. The model of $P$. brutia shows a more constant growth rate (Fig. 2). The dominant height developments predicted by the models resemble well the actual dominant height growth pattern in the modelling data (Fig. 2).

\subsection{Diameter growth models}

\subsubsection{Pinus brutia}

All parameter estimates of the diameter growth model (Eq. (4)) and the plot factor models (Eqs. (6) and (7)) for $P$. brutia were logical and significant at the 0.001 level (Tab. V). The $R^{2}$ value of the diameter growth model was 0.372 . The $R^{2}$ values of the random plot factor models were 0.072 and 0.107 , respectively, when using $S I$ and $G I$ as a predictor, implying that only a small part of the variation in plot factor was explained by site productivity. Both untransformed dbh and the transformation $\ln (d)$ were significant predictors, and together they describe the non-linear pattern between diameter increment and $d b h$. BAL was also a significant predictor, which explained the effect of competition on diameter growth. The plot factor models (Eqs. (6) and (7)) used Sdepth as predictor with either $S I$ or GI. The shape of the relationship between $\mathrm{dbh}$ and diameter growth was biologically sound (Fig. 3). Diameter increment increases to a maximum at $\mathrm{dbh}$ of $20 \mathrm{~cm}$ and then slowly decreases. In addition, increasing competition (BAL) decreased the diameter growth of a tree (Fig. 3).

The accuracy of the diameter growth prediction was better when using the true plot factor than when using the plot factor models to predict the plot factor (see Tab. V). The bias and RMSE of the $P$. brutia diameter growth model was $-0.016 \mathrm{~cm}$ and $1.134 \mathrm{~cm}$ respectively, when using Equation (6) to predict the plot factor, while bias was $0.001 \mathrm{~cm}$ and RMSE was $1.114 \mathrm{~cm}$ when using Equation (7) to predict the plot factor (Tab. V). The biases of the diameter growth models, when the fixed model part and the plot factor models were used, show no obvious dependencies or patterns that indicate systematic trends between the residuals and the independent variables.

\subsubsection{Oaks}

The diameter growth model for the accompanying oaks was more simple since only two logical predictors were significant; elevation $($ Ele $)$ and stand basal area $(\ln (G))$. Ele had a positive effect on oak diameter growth while greater values of $G$ (which represented higher competition in the stand) produced lower diameter growths. The $R^{2}$ was 0.164 for the diameter growth model, and 0.066 and 0.091 , respectively, for the plot factor models when using $S I$ or $G I$ as a predictor. The accuracy of the oak model, in terms of bias and RMSE (Tab. V), was lower than for P. brutia models.

\subsection{Height models}

Due to the form of Equation (8), which can be used in evenaged stands, the height of a tree with dbh equal to dominant diameter is equal to the dominant height of the stand. Equation (9), which can be used in even-aged and uneven-aged stands, describes tree height as a function of diameter at breast height and GI. According to the model, improving GI results in taller trees with a given dbh. The $R^{2}$ of the height models using Equation (8) was 0.761 for P. brutia and 0.544 for oaks (Tab. VI). The $R^{2}$ of models using Equation (9) was 0.672 for $P$. brutia and 0.344 for oaks (Tab. VI). The precision of the models fitted with Equation (8) was higher than the models fitted with Equation (9). However, the models fitted with Equation (9) were slightly less biased (Tab. VI). The relative bias of the height models varied from $0.016 \%$ (oak model using Eq. (9)) to $1.095 \%$ (P. brutia model using Eq. (8)). The relative RMSE varied from $18 \%$ for the $P$. brutia model using Equation (8) to $26 \%$ for the oak model using Equation (9) (Tab. VI). 


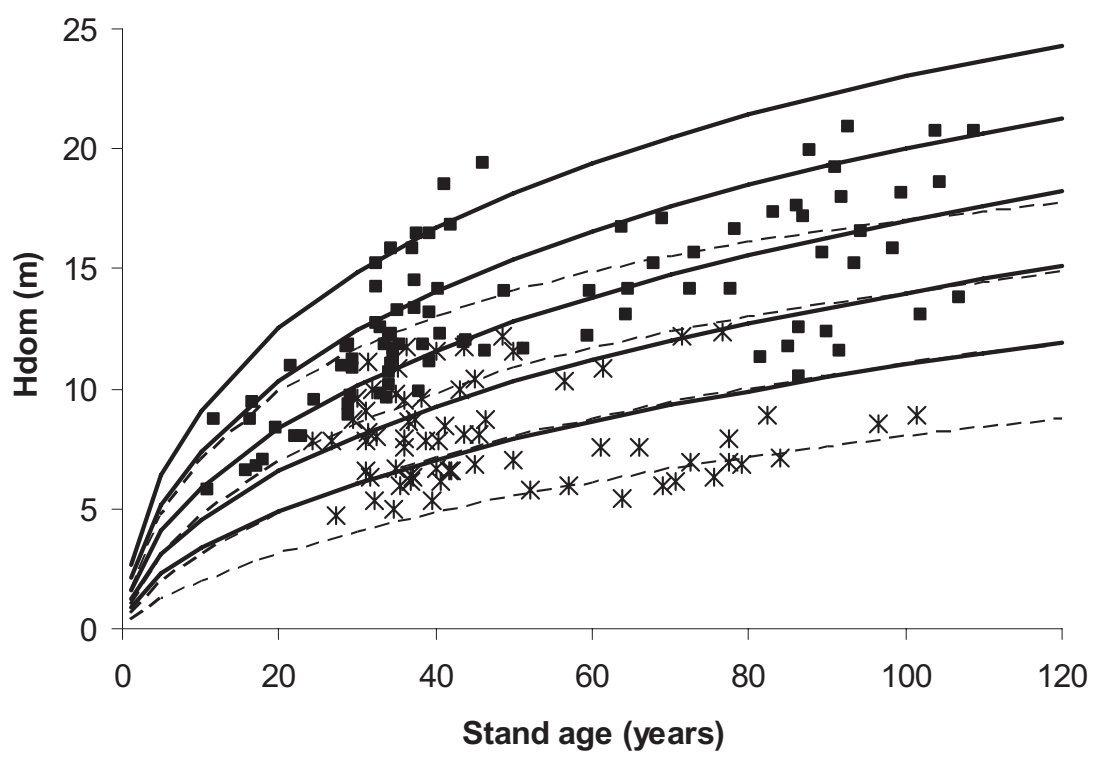

Figure 2. Comparison of the site index curves for P. brutia (solid line) and oaks (dashed line) developed in this study with the modeling data used. The site index curves presented illustrate dominant height development for site indices 11, 14, 17 and $20 \mathrm{~m}$ for $P$. brutia and for site indices $8,11,14$ and $17 \mathrm{~m}$ for oak stands (at an index age of 100 years). The observed dominant heights are indicated by squares ( $P$. brutia) or asterix (oaks).

Table V. Estimates of the parameters, variance components $\left(\sigma_{p l}^{2}, \sigma_{e}^{2}\right)$ and coefficient of determination $\left(R^{2}\right)$ of the diameter growth models (Eqs. (4) and (5)) and the corresponding plot factor models (Eqs. (6) and (7)). The biases and RMSEs are for the diameter increment calculated with either known (Eqs. (4) and (5)) or predicted (Eqs. (6) and (7)) plot factors. $\sigma_{p l}^{2}$ between-plot residual variance, $\sigma_{e}^{2}$ between-tree within plot residual variance.

\begin{tabular}{|c|c|c|c|c|c|c|}
\hline \multirow{3}{*}{ Parameter } & \multicolumn{3}{|c|}{ Pinus brutia } & \multicolumn{3}{|c|}{ Oaks } \\
\hline & \multirow{2}{*}{$\begin{array}{c}\text { Diameter } \\
\text { growth model } \\
\text { Eq. (4) }\end{array}$} & \multicolumn{2}{|c|}{ Plot factor models } & \multirow{2}{*}{$\begin{array}{c}\text { Diameter } \\
\text { growth model } \\
\text { Eq. (5) }\end{array}$} & \multicolumn{2}{|c|}{ Plot factor models } \\
\hline & & $S I$ & $G I$ & & $S I$ & $G I$ \\
\hline$\overline{\beta_{0}}$ & 0.359 & -0.621 & -0.756 & 1.592 & -0.321 & -0.338 \\
\hline$\beta_{1}$ & -0.056 & 0.009 & 0.007 & 0.001 & 0.001 & 0.002 \\
\hline$\sigma_{p l}^{2}$ & 0.494 & - & - & 0.096 & - & - \\
\hline$\sigma_{e}^{2}$ & 0.890 & 0.369 & 0.355 & 0.573 & 0.059 & 0.057 \\
\hline$R^{2}$ & 0.372 & 0.072 & 0.107 & 0.164 & 0.066 & 0.091 \\
\hline Bias of $i d$ & 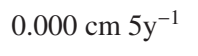 & $-0.016 \mathrm{~cm} 5 \mathrm{y}^{-1}$ & $0.001{\mathrm{~cm} 5 y^{-1}}^{-1}$ & 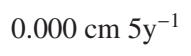 & 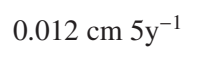 & $0.011{\mathrm{~cm} 5 y^{-1}}^{-1}$ \\
\hline
\end{tabular}

\subsection{Survival models}

The probability of a $P$. brutia tree to survive was best explained by $\ln (d)$ and $\ln (G)$ (Eqs. (10) and (11), Tab. VII). The larger the diameter of the tree (indicating greater tree size) and the smaller the basal area (indicating less two-sided competition) of the stand the higher was the probability of a P. brutia tree to survive the next 5 years. The survival probability of oaks was best explained by $\ln (G)$ and $d^{-1}$. This model also predicts greater survival probabilities for larger trees (big diameters) and low competition (low basal areas). Site variables were not significant predictors in the two survival models. The Wald tests show that the parameter estimates in Table VI are significant $(P<0.05)$.

The relative area below an ROC curve is a measure of accuracy, and its range is from 0.5 (chance) and 1.0 (perfect) (Saveland and Neuenschwander, 1990). The relative area below the ROC for Equation (10) was greater than for Equation (11), 

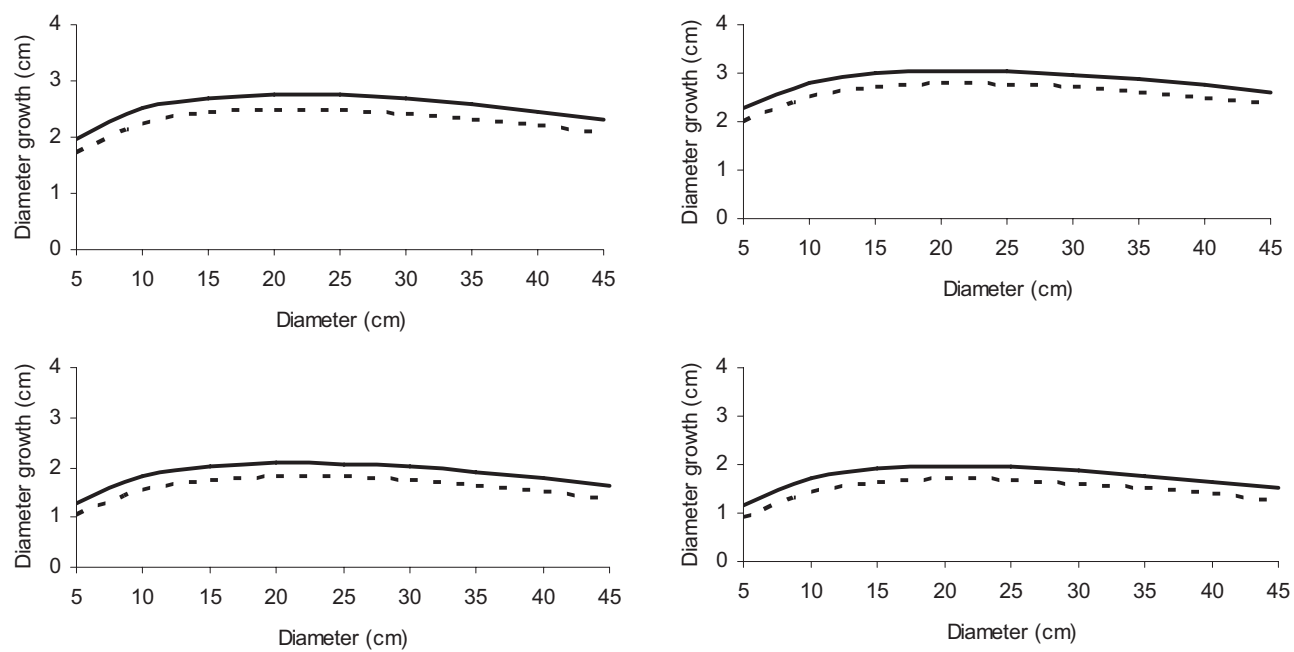

Figure 3. Diameter growth for $P$. brutia as a function of dbh and $B A L$ for a fertile (above) and poor site (below) when using Equation (6) (left) or Equation (7) (right) to predict the plot factor (solid line: $B A L=10 \mathrm{~m}^{2} \mathrm{ha}^{-1}$; dotted line: $B A L=20 \mathrm{~m}^{2} \mathrm{ha}^{-1}$ ).

Table VI. Estimates of the parameters, residual variance $\left(\sigma_{e}^{2}\right)$, coefficient of determination $\left(R^{2}\right)$ and absolute and relative biases and RMSEs of the height models (Eqs. (8) and (9)).

\begin{tabular}{|c|c|c|c|c|}
\hline \multirow[b]{2}{*}{ Parameter } & \multicolumn{2}{|c|}{ Pinus brutia } & \multicolumn{2}{|c|}{ Oaks } \\
\hline & Eq. (8) & Eq. (9) & Eq. (8) & Eq. (9) \\
\hline$\overline{\beta_{0}}$ & 0.532 & 42.194 & 0.584 & 23.501 \\
\hline$\beta_{1}$ & -0.022 & -8.417 & -0.124 & -3.547 \\
\hline$\beta_{2}$ & - & 47.422 & - & 20.576 \\
\hline$\beta_{3}$ & - & -124.068 & - & -24.810 \\
\hline$\sigma_{e}^{2}$ & 3.690 & 5.077 & 2.721 & 3.922 \\
\hline$R^{2}$ & 0.761 & 0.672 & 0.544 & 0.344 \\
\hline Bias & $0.112 \mathrm{~m}$ & $0.007 \mathrm{~m}$ & $0.002 \mathrm{~m}$ & $0.001 \mathrm{~m}$ \\
\hline Bias \% & 1.095 & 0.073 & 0.026 & 0.016 \\
\hline RMSE & $1.920 \mathrm{~m}$ & 2.251 & $1.649 \mathrm{~m}$ & $1.978 \mathrm{~m}$ \\
\hline RMSE \% & 18.689 & 21.687 & 21.473 & 25.767 \\
\hline
\end{tabular}

Table VII. Estimated parameters, their standard errors (S.E.), statistical significance and odds ratios for the logistic mortality models (Eq. (10) and Eq. (11) $)^{\mathrm{a}}$.

\begin{tabular}{|c|c|c|c|c|c|}
\hline Parameter & Estimate & S.E & Wald statistics & Significance & Odds ratio $(\exp (\beta))$ \\
\hline \multicolumn{6}{|c|}{ Pinus brutia (Eq. (10)) } \\
\hline$\beta_{0}$ & -1.063 & 0.687 & 2.393 & 0.122 & 0.345 \\
\hline$\beta_{1}$ & 1.941 & 0.212 & 84.117 & 0.000 & 6.965 \\
\hline$\beta_{2}$ & -0.634 & 0.173 & 13.448 & 0.000 & 0.530 \\
\hline$\chi^{2}-$ value & 109.296 & & & & \\
\hline \multicolumn{6}{|c|}{ Oaks (Eq. (11)) } \\
\hline$\beta_{0}$ & 5.862 & 0.612 & 91.749 & 0.00 & 351.460 \\
\hline$\beta_{1}$ & -0.452 & 0.123 & 13.411 & 0.00 & 0.636 \\
\hline$\beta_{2}$ & -16.212 & 3.632 & 19.926 & 0.00 & 0.000 \\
\hline$\chi^{2}-$ value & 26.514 & & & & \\
\hline
\end{tabular}

${ }^{\text {a }} \chi^{2}$ : Chi-square value. 
Table VIII. Mean, Standard deviation (S.D.) and range of the number of trees per hectare and their mean dbh entering the first dbh-class during a five year period.

\begin{tabular}{|c|c|c|c|c|}
\hline Variable & Mean & Standard deviation & Minimum & Maximum \\
\hline \multicolumn{5}{|l|}{ Oaks } \\
\hline Number of trees $\left(\mathrm{ha}^{-1}\right)$ & 13.68 & 41.06 & 0.00 & 300.00 \\
\hline \multicolumn{5}{|l|}{ Pinus brutia } \\
\hline Number of trees $\left(\mathrm{ha}^{-1}\right)$ & 6.32 & 23.63 & 0.00 & 150.00 \\
\hline
\end{tabular}

which means that the accuracy of the individual-tree survival model for Pinus brutia was better that the survival model for oak (Fig. 1). The $\chi^{2}$-values for the Pinus brutia and oak individual-tree survival models were respectively 109 and 26 (see Tab. VII).

\subsection{Ingrowth}

The mean number of trees that enter the first diameter class (pass the 5-cm limit) during a 5-year period was about $20 \mathrm{ha}^{-1}$, of which $2 / 3$ were oaks (Tab. VIII). The ranges were wide: from 0 to 300 for oak and from 0 to 150 for pine. The ingrowth pines were about $9 \mathrm{~cm}$ in dbh and the oaks were about $8 \mathrm{~cm}$ at the end of the 5-year period.

\subsection{Simulation results}

The two sets of models were used to simulate the development of representative plots of the study material. Two evenaged pine stands, one representing a medium site $(S I 18.6 \mathrm{~m}$, GI 1.07) and the other a good site (SI $24.7 \mathrm{~m}$, GI 2.26) were used in simulations (Fig. 4). Ingrowth was not simulated because the schedules represented even-aged forestry in which the possible ingrowth is not normally utilised. The two sets of models produced similar results in terms of stand density and mean diameter development (especially for the medium site). This is in line with the evaluation results of the diameter growth models, which did not show big differences in their performance. Some differences were observed in the mean height development for the better site.

The development of an even-aged oak stand on a medium site ( $S I 10.11 \mathrm{~m}, G I$ is 0.92 ) was simulated using the two sets of models (Fig. 5). Again the two types of models were similar in predicting the development of stand density and mean diameter. However, there was a great difference between the models in the development of mean height.

The models using GI as the site descriptor were used to simulate the development of uneven-aged mixed stand (Fig. 6). The simulation indicates that the proportion of oaks gradually increases (from 55 to $62 \%$ of the number of trees during the simulation period). However, the diameter growth of pines is continuously faster with a consequence that the size difference between the species increases.
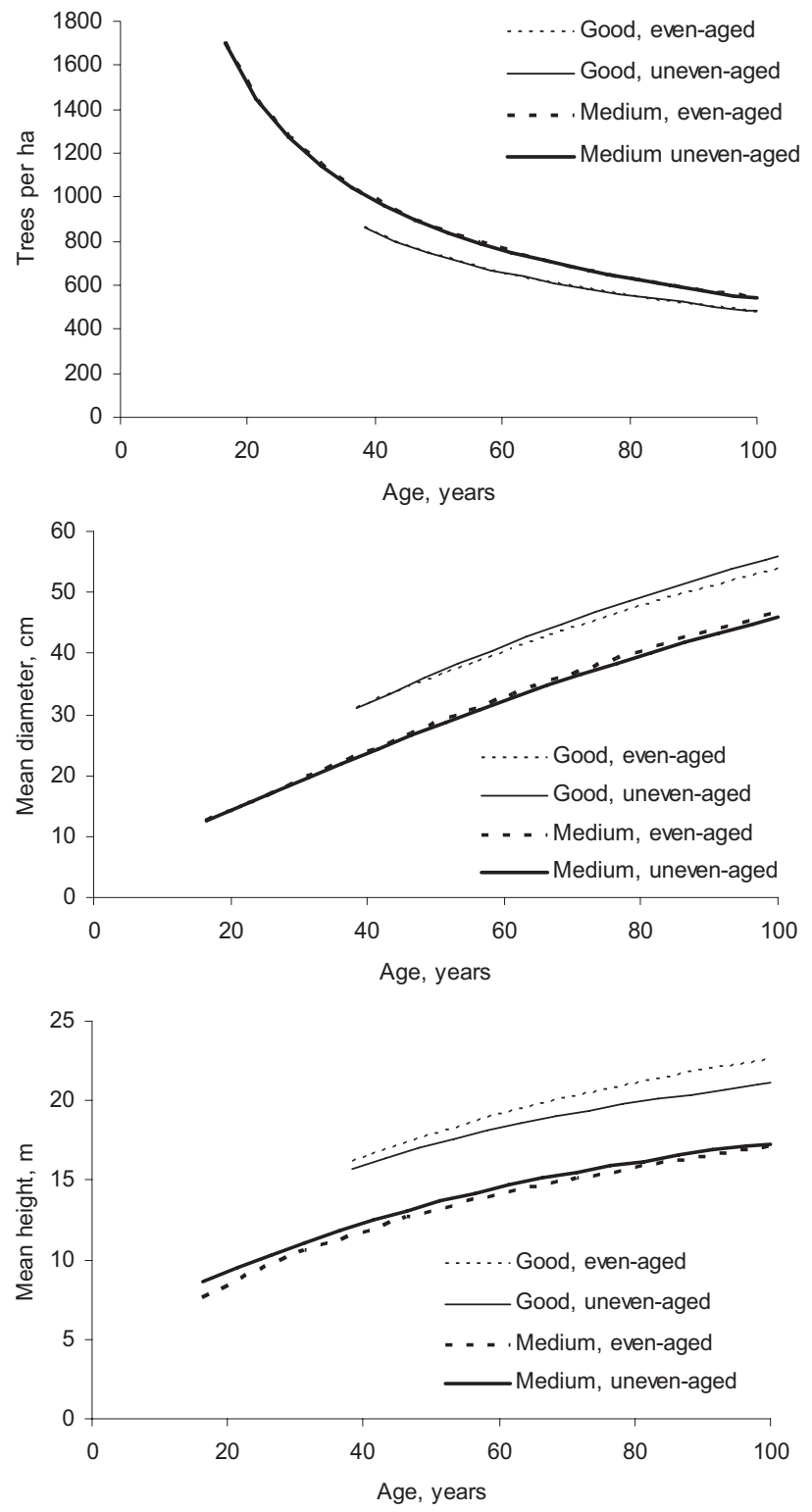

Figure 4. Simulated development of two even-aged $P$. brutia stands representing good (SI $24.7 \mathrm{~m}$, GI 2.26) and medium (SI $18.6 \mathrm{~m}$, GI 1.07 ) sites using the two sets of models (for even-aged and unevenaged forestry). 

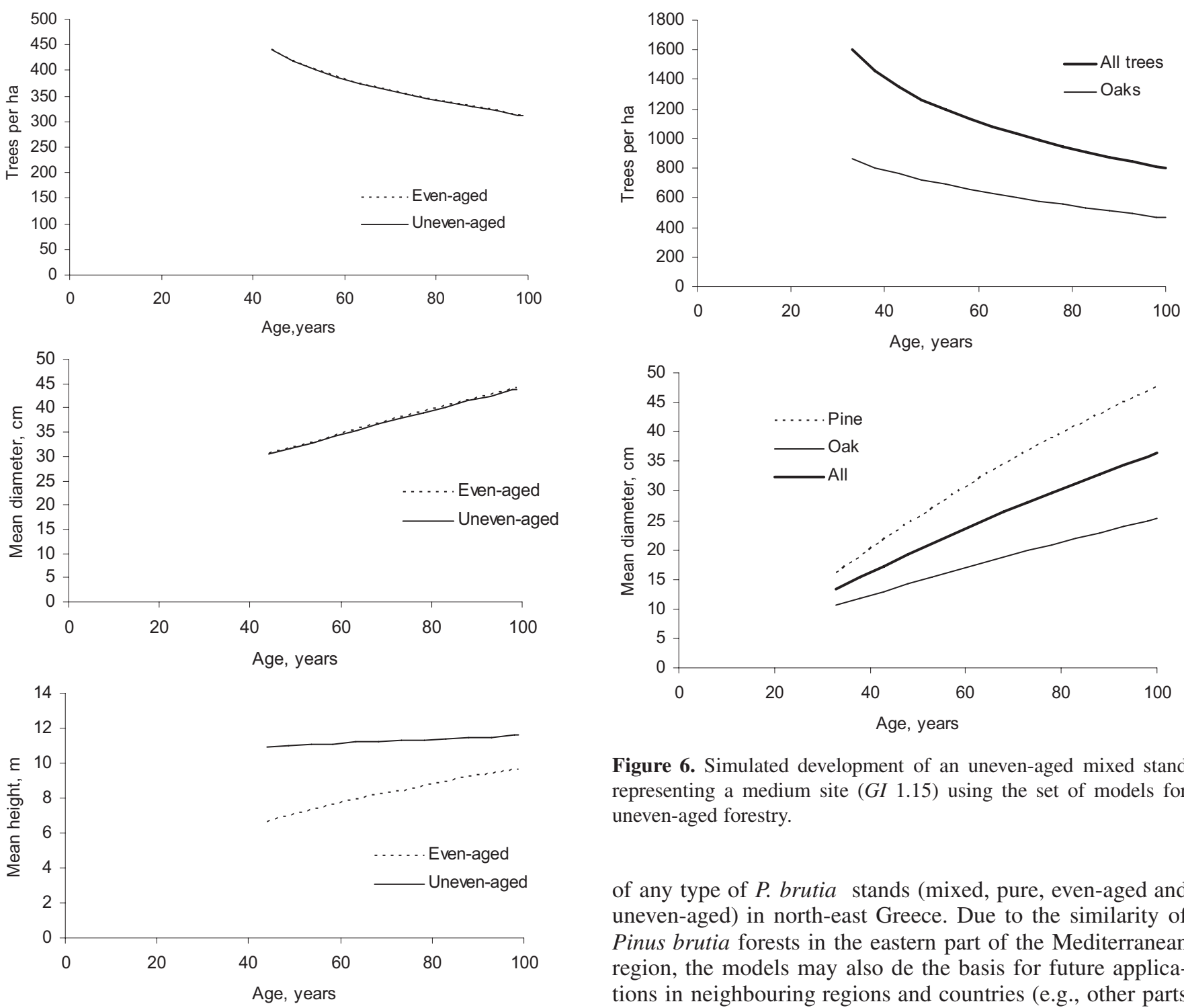

Figure 5. Simulated development of an even-aged oak stand representing a medium site (SI $10.11 \mathrm{~m}, G I$ is 0.92$)$ using the two sets of models (for even-aged and uneven-aged forestry).

The complete set of models for uneven-aged forestry (including ingrowth) was used for a long-term simulation of the development of an uneven-aged mixed stand (Fig. 7). The over 400-year simulation showed that the initially pine dominated stand would be dominated by oaks at the end of the period, since the number of oak trees constantly increased while the number of pines decreased. The mean, maximum and minimum diameter development is also realistic. When the stand reaches a steady state the mean diameter is of $40 \mathrm{~cm}$, while some trees are $100 \mathrm{~cm}$, thick.

\section{DISCUSSION}

This study presented, for the first time, site quality models and individual-tree models for predicting the development

Figure 6. Simulated development of an uneven-aged mixed stand representing a medium site (GI 1.15) using the set of models for uneven-aged forestry.

of any type of $P$. brutia stands (mixed, pure, even-aged and uneven-aged) in north-east Greece. Due to the similarity of Pinus brutia forests in the eastern part of the Mediterranean region, the models may also de the basis for future applications in neighbouring regions and countries (e.g., other parts of Greece, Bulgaria, Turkey).

Although the study plots used in developing the models were assumed to represent forest stands (homogeneous subareas of forests), we were aware of the sampling error problem arising from their small size. However, since the study plots were rather small, calculation of model predictors includes sampling error which may have brought same "flattening" effect on the regression coefficients. In addition, the modelling data had a limited time span (i.e. one measurement interval only).

The selection of the site index model was based on biological considerations such as the value of the asymptote, the growth pattern at young ages, the biological realism of the site index curves when compared to the modelling data (see Fig. 2) and the quality of extrapolations out of the site range of the data. Although the modelling data covered a wide range of stand ages, the data had obvious limitations (e.g., only one growth interval). Due to the fact that no other dominant height growth models for $P$. brutia seem to have been published it was not possible to assess the models on the basis of earlier 

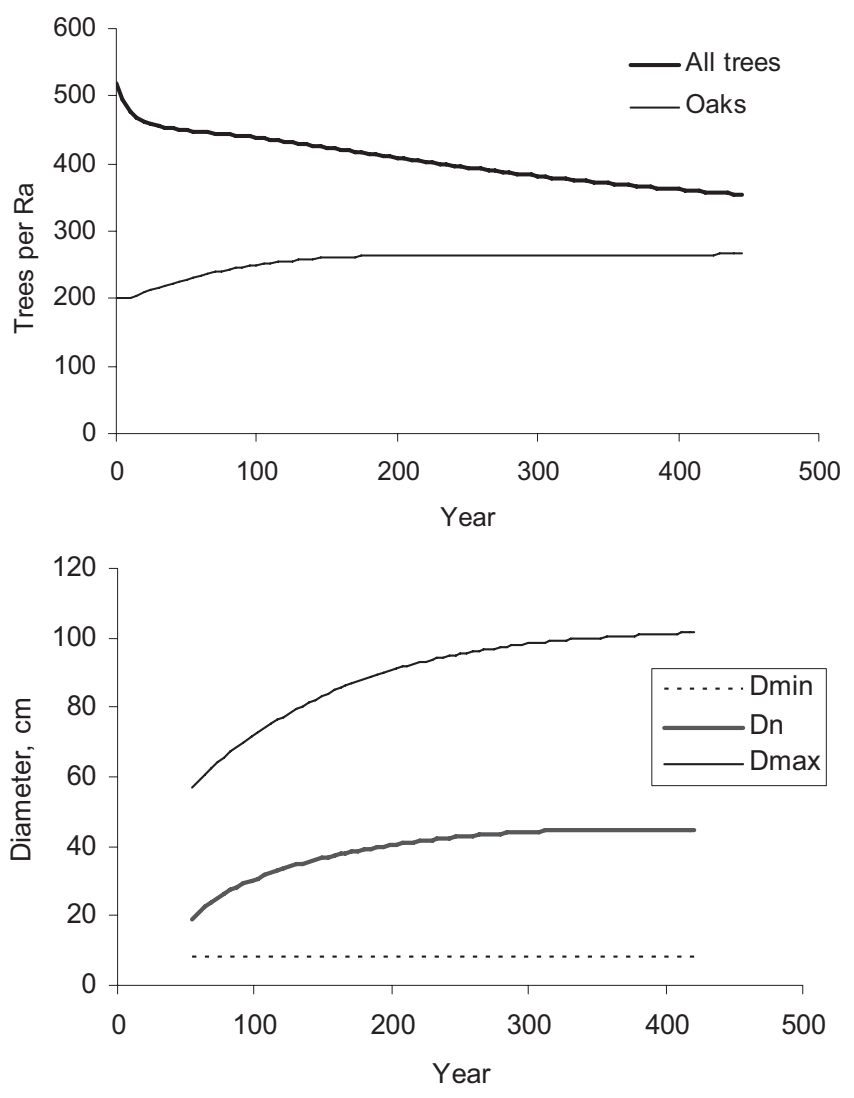

Figure 7. Long-term simulation of the development of an unevenaged mixed stand representing a medium site (GI 1.15) using the set of models for uneven-aged forestry (and simulating ingrowth).

research. Figure 1 shows that the dominant height curves developed resemble well the trend in the modelling data.

The asymptotic parameter of the $P$. brutia dominant height growth model was as high as $48 \mathrm{~m}$, which forces the dominant height to continue growing at rather old ages. Therefore, it is recommended that the site index model is not used out of the age range of the modelling data. The site index curves were not s-shaped, giving at young ages high growth rates. However, since there were not many observations from stands younger than 20 years, it is difficult to evaluate whether the models show the right growth pattern of young stands.

The asymptotic parameter of the dominant height growth model for oaks was $25 \mathrm{~m}$, which seems rather realistic from the biological point of view. The site index model for oak was compared to the one by Gatzojannis and Grigoriadis (2000) which was developed for the same area. However, this earlier model showed a pronounced non-asymptotic trend especially for the best sites, which did not resemble our observed data.

The growth index was based on the prediction of past growth of trees growing on average site; the prediction past growth models used tree size and competition descriptors as predictors, but omitted site. This approach was based on the assumption that all site fertility levels were evenly represented in different classes of tree size and competition. However, this seldom happens in practice. Therefore, when the effect of tree size and competition was extracted from the measured past growth of the subject tree, probably part of the site effect was as well removed. Despite this limitation, the calculated growth index accounted for both local and site effects and could explain variation in the random plot factor equally well as site index. In fact, growth index and site index are not distant concepts, since both evaluate site based on measured past growth; periodical past diameter growth (growth index) or dominant height growth (site index).

A disadvantage in modelling the diameter growth was that in the first measurement tree diameters were recorded only with an accuracy of one $\mathrm{cm}$ (rounded to the closest full $\mathrm{cm}$ ). This resulted in low precision of the diameter increment observations and many negative diameter increment values (see Tab. II). However, negative diameter increment values were kept in the modelling data in order to avoid having a biased data set. The inaccuracy of data is reflected in the coefficients of determination, which are rather low. The precision of the diameter growth predictions, therefore, needs to be viewed within this data constraint.

Diameter was not a significant predictor in the past growth or the diameter increment model of oak because there was not enough size variation in oak to capture the usual effect (seen in the pine model). Most oaks present in the modelling data were small trees that have regenerated under the pines.

The developed diameter increment models included a fixed part and two random parameters, one for between-plot variation and the other for within-plot between-tree variation. Modelling diameter increment in this way has been proposed, among others, by Calama and Montero (2005), Palahí et al. (2003), Stage (1973), Trasobares et al. (2004a), Wycoff et al. (1982). Incorporating the stochastic between-plot structure in the model alleviated problems associated with the presence of nested structure (Fox et al., 2001), which otherwise may result in biased estimates of standard errors of parameter estimates. The inclusion of the between-plot random factor is the reason why site variables were not significant when fitting the diameter increment models using a mixed model approach. However, the between-plot factors correlated logically with site variables like Sdepth, SI or GI. This is why site variables were used to develop models that predict the plot factors of the diameter increment models.

Diameter growth predictions for Pinus brutia trees of dbhclass $25 \mathrm{~cm}$ (which had the highest growth increments) varies between $1.5 \mathrm{~cm}$ to almost $3 \mathrm{~cm}$ depending on site quality and competition. These increments are similar to the ones found for pines elsewhere in the Mediterranean region (Palahí and Grau Corbí, 2003; Palahí et al., 2003).

The ingrowth and survival models do not have a strong impact on short-term simulations, but they are crucial in producing unbiased and realistic long-term simulations. The ingrowth prediction should be used with caution since it is just the average number of trees entering the first diameter class. Such average will under-predict the ingrowth in forest with low stand occupation, while it will overpredict it in very dense stands. As soon as new data becomes available a more reliable ingrowth model should be developed. 
The survival models show also some weaknesses with very large trees, since the models predict increasing survival probability with increasing diameter, while there is empirical evidence that very large trees (older trees) have less probability to survive. Vanclay (1994) proposed the use of squared diameter to include the full effect of tree size in mortality (approaching zero for very large values of diameter). However, in this study the squared diameter was not significant. Furthermore, site variables (site index or growth index) were not significant predictors in the survival models. Previous studies (see Vanclay, 1994) mentioned that the effect of site on tree mortality is unclear since; although there is empirical evidence that better sites can sustain higher basal area, there are some studies showing that mortality begins earlier in good sites (Eid and Tuhus, 2001). The survival models of this study (Eqs. (10) and (11)) show that the probability of survival increases for Pinus brutia and oaks when the overall competition (represented by $G$ ) decreases and tree size increases (represented by tree diameter). Oaks have a clearly higher probability to survive than $P$. brutia trees of the same size for the same stand basal area. Therefore, the models reflect well the ecology of the two species since oaks are known to be more shade tolerant and capable of regenerating and developing under tree canopies, while $P$. brutia trees are more light demanding and require better competitive situations to increase their survival probability.

Simulations (Figs. 4-7) were used to demonstrate how the models work together in medium and long-term growth and yield prediction. The simulations suggest that the two types of models provide realistic predictions of forest stand development and allow one to simulate the development of complex Pinus brutia stand structures in Dadia NP forests. When both types of models could be tested for the same stand, similar developments were found in terms of mean diameter and stand density. On the other hand, there were clear differences in the mean height predictions made by the two types of models. This is partly explained by the fact that the starting heights were also calculated by the models. However, due to the lack of validation data it is difficult to say which of the two types of height models performed better. In any case, it is obvious that height models for uneven-aged forestry should be used in a mixed and uneven-aged stands, while in even aged pure stands, for which site index is known, the models for evenaged forestry utilise more efficiently the available information.

The simulation exercises corresponding to Figures 4 to 6 were also used to compute the annual volume increments for different stand types (see Fig. 8). In a good site a pine stand achieved the maximum annual volume increment (around $8.5 \mathrm{~m}^{3} \mathrm{ha}^{-1}$ ) at 40 years while in a medium site the maximum increment was at 50 years and equalled $6 \mathrm{~m}^{3} \mathrm{ha}^{-1}$. The pure oak stand showed a rather constant annual volume increment of about $1 \mathrm{~m}^{3} \mathrm{ha}^{-1}$, and the mixed stand achieved its maximum volume increment $\left(5 \mathrm{~m}^{3} \mathrm{ha}^{-1}\right)$ at around 60 years. Together the simulation results suggest that the annual volume increment of the Dadia NP forests is $1-8 \mathrm{~m}^{3} \mathrm{ha}^{-1} \mathrm{y}^{-1}$.

The study compared two different model approaches, one of them (called as the uneven-aged approach) using a rather

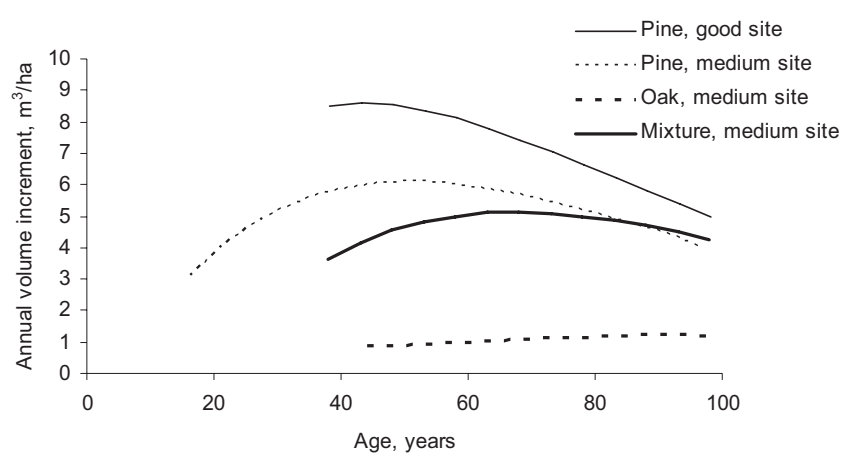

Figure 8. Annual volume increments in four simulations (presented in Figs. 3 to 5): (i) a good site even-aged pine stand (SI $24.7 \mathrm{~m}$, GI 2.26) (ii) a medium site even-aged pine stand (SI $18.6 \mathrm{~m}$, (GI 1.07), (iii) a medium site even-aged oak stand (SI $10.11 \mathrm{~m}, G I$ is 0.92$)$ and (iv) a medium site uneven-aged mixed stand (GI 1.15).

easily measurable growth index $(G I)$ as a way to evaluate site productivity. The overall fitting statistics results showed that the $G I$ was feasible and effective predictor of site quality and the set of models which used such variable as predictor performed in a similar way as the models using SI, which require more information (Hdom and $T$ ) and a given stand structure (even aged).

Tomé et al. (2006) recently proposed a new approach based on the use of age-independent difference equations for modelling tree (diameter) and stand (dominant height) growth in situations where age is not known and different levels of site quality information are available. They concluded that ageindependent growth models performed equally well as agebased models, providing similar prediction ability.

The models presented in our study can be further used to develop appropriate simulation tools and decision support systems to support forestry decision-making at different scales (stand, forest, landscape) in Dadia NP. In stand-level management planning, the above models can be used together with optimization techniques (Palahí and Pukkala, 2003), to conduct comparative analyses on the effects of economic or biological factors on stand management. For instance, optimal management schedules for maximizing timber production and at the same time addressing raptor habitats, which are very important in Dadia NP, can be found by using simulation-optimization tools based on the models presented above. In addition, the models can be used to support forest and landscape level decisions by providing information on alternative management regimes for the different stand compartments of the forest.

Acknowledgements: This study has been supported by the research project "EPEAEK II - PYTHAGORAS II: 1329-1", co-funded by the European Social Fund and the Greek Ministry of Education. Part of the study has been supported by the Accion Complementaria: AGL2004-0255-E funded by the Ministerio de Educación y Ciencia of Spain, Secretaria de Política Científica y Tecnológica. The authors wish to thank WWF Greece for their kind assistance during sampling and Dr. S. Gatzojannis for useful comments on the manuscript. 


\section{REFERENCES}

Amaro A., Reed D., Tomé M., and Themido I., 1998. Modeling dominant height growth: Eucalyptus plantations in Portugal. For. Sci. 44: $37-46$.

Adamakopoulos T., Gatzogiannis S., and Poirazidis K., 1995. Special environmental study for the Dadia Forest Reserve, WWF Greece, Athens, 440 p. (in Greek).

Apatsidis D.L., 1995. Construction of normal yield tables for oak. In: Greek Forestry Society (Ed.), Utilization of Forest Resources, Proceedings of the 7th Greek Forestry Conference, Karditsa 11-13 October 1994, pp. 317-333.

Calama R. and Montero G., 2005. Multilevel linear mixed model for tree diameter increment in stone pine (Pinus pinea): a calibrating approach. Silva Fenn. 39: 37-54.

Chatziphilippidis G. and Spyroglou G., 2006. Modeling the growth of Quercus frainetto in Greece. In: Hasenauer H. (Ed.), Sustainable Forest Management - Growth Models for Europe, Springer, Berlin - Heidelberg, pp. 373-393.

Cieszewski C.J. and Bailey R.L., 2000. Generalized algebraic difference approach: Theory based derivation of dynamic equations with polymorphism and variable asymptotes. For. Sci. 46: 116-126.

Clutter J.L., Forston J.C., Piennar L.V., Brister G.H., and Bailey R.L., 1983. Timber management-a quantitative approach, Wiley, New York, p. 333.

Eid T. and Tuhus E., 2001. Models for individual tree mortality in Norway. For. Ecol. Manage. 154: 69-84.

Fox J.C., Ades P.K., and Bi H., 2001. Stochastic structure and individualtree growth models. For. Ecol. Manage. 154: 261-276.

González J.R., Trasobares A., Palahí M., and Pukkala T., 2007. Predicting tree survival in burned forests in Catalonia (North-East Spain) for strategic forest planning. Ann. For. Sci. 64: 733-742.

Gatzojannis S. and Grigoriadis N., 2000. Ein polymorphes Höhenmodell für Quercus frainetto Bestände im Waldgebiet Arnäa (Griechenland). Allg. Forst-u. J. -Ztg. 171: 67-74.

Hynynen J., 1995. Predicting the growth response to thinning for Scots pine stands using individual-tree growth models. Silva Fenn. 29: 225-246.

Kati V., Devillers P., Dufrêne M., Legakis A., Vokou D., and Lebrun P., 2004. Testing the value of six taxonomic groups as biodiversity indicators at a local scale. Conserv. Biol. 18: 667-675.

Kossenakis T.T., 1939. Yield tables of coppice stands of Quercus frainetto, Fagus sylvatica and Castanea sativa, Forest Research Publications Bureau, Ministry of Agriculture, Athens, 56 p. (in Greek).

McDill M.E. and Amateis R.L., 1992. Measuring forest site quality using the parameters of a dimensionally compatible height growth function. For. Sci. 38: 409-429.

Palahí M. and Grau Corbí J., 2003. Preliminary site index model and individual-tree growth and mortality models for black pine (Pinus nigra Arn.) in Catalonia (Spain). Investig. Agrar. Sist. Recur. For. 12: $137-148$

Palahí M. and Pukkala T., 2003. Optimising the management of Scots pine (Pinus sylvestris L.) stands in Spain based on individual-tree models. Ann. For. Sci. 60: 105-114.

Palahí M., Pukkala T., Miina J., and Montero G., 2003. Individual-tree growth and mortality models for Scots pine (Pinus sylvestris L.) in north-east Spain. Ann. For. Sci. 60: 1-10.
Palahí M., Tomé M., Pukkala T., Trasobares A., and Montero G., 2004. Site-index model for Pinus sylvestris in north-east Spain. For. Ecol. Manage. 187: 35-47.

Peschel W., 1938. Die mathematischen Methoden zur Herleitung der Wachstumsgesetze von Baum und Bestand und die Ergebnisse ihrer Anwendung. Tharandter Forstl. Jahrb. 89: 169-247.

Pienaar L.V. and Turnbull K.J., 1973. The Chapman-Richards generalization of Von Bertalanffy's growth model for basal area growth and yield in even-aged stands. For. Sci. 19: 2-22.

Pita P.A., 1964. La calidad de la estación en las masas de Pinus sylvestris de la Península Ibérica. Anales del Instituto Forestal de Investigaciones y Experiencias 9: 5-28.

Poirazidis K., Skartsi T., and Catsadorakis G., 2002. Monitoring plan for the protected area of Dadia-Lefkimi-Soufli Forest, WWF Greece, Athens, $126 \mathrm{p}$.

Poirazidis K., Goutner V., Skartsi T., and Stamou N., 2004. Modelling nesting habitat as a conservation tool for the Eurasian black vulture (Aegypius monachus) in Dadia Nature Reserve, northeastern Greece. Biol. Conserv. 118: 235-248.

Poirazidis K., Goutner V., Tsachalidis E., and Kati V., 2007. Nesting habitat differentiation among four sympatric forest raptors in the Dadia National Park, Greece. Anim. Biodivers. Conserv. 30: 131-142.

Sanchez-Gonzalez M., Tomé M., and Montero G., 2005. Modelling height and diameter growth of dominant cork oak trees in Spain. Ann For. Sci. 62: 633-643.

Saveland J.M. and Neuenschwander L.F., 1990. A signal detection framework to evaluate models of tree mortality following fire damage, For. Sci. 36: 66-76.

Schindler S., Poirazidis K., and Wrbka T., 2008. Towards a core set of landscape metrics as a prerequisite for biodiversity assessments: a case study from Dadia NP, Greece. Ecological Indicators, 8: 502514.

Schumacher F.X., 1939. A new growth curve and its application to timber yield studies. J. For. 37: 819-820.

SPSS Inc., 2005. SPSS base system syntax reference guide, release 14.0.

Soares P. and Tomé M., 2003. GLOBTREE: an individual tree growth model for Eucalyptus globulus in Portugal. In: Amaro A., Reed D., and Soares P. (Eds.), Modelling Forest Systems, CAB International, Walingford, pp. 97-110.

Stage A.R., 1973. Prognosis model for stand development, USDA Forest Service, Research Paper INT-137, p. 32.

Tomé J., Tomé M., Barreiro S., and Amaral Paulo J., 2006. Ageindependent difference equations for modelling tree and stand growth. Can. J. For. Res. 36: 1621-1630.

Trasobares A., Pukkala T., and Miina J., 2004a. Growth and yield model for uneven-aged mixtures of Pinus sylvestris L. and Pinus nigra Arn. in Catalonia, north-east Spain. Ann. For. Sci. 61: 9-24.

Trasobares A., Tomé M., and Miina J., 2004b. Growth and yield model for Pinus halepensis Mill. in Catalonia, north-east Spain. For. Ecol. Manage. 203: 49-62.

Vanclay J.K., 1994. Modelling forest growth and yield: Applications to mixed tropical forests, CABI Publishing, Walingford, UK, p. 312.

Wycoff W., Crookston N.L., and Stage A.R., 1982. User's guide to the stand prognosis model, USDA Forest Service, General Technical Report INT-133, p. 114.

Wycoff W., 1990. A basal area increment model for individual conifers in the northern Rocky Mountains. For. Sci. 36: 1077-1104. 